\title{
SISTEMAS DE INFORMAÇÃO EM BIBLIOTECAS: O COMPORTAMENTO DOS USUÁRIOS E BIBLIOTECÁRIOS FRENTE ÀS NOVAS TECNOLOGIAS DE INFORMAÇÃO ${ }^{1}$
}

\section{Patrícia Maria Silva}

\section{Resumo:}

A Tecnologia da Informação influencia o trabalho intelectual e de pesquisa nas várias áreas do conhecimento. Nas bibliotecas a tecnologia é utilizada através dos Sistemas de Informação para armazenar, manipular, filtrar e gerar informação de forma rápida e eficaz. O presente trabalho pretende colaborar para o aprofundamento do conhecimento sobre algumas questões fundamentais no uso de Sistemas de Informação em bibliotecas. Busca compreender e identificar melhor os determinantes e barreiras de usabilidade, que leva a não interação usuário/sistema. O estudo foi conduzido a partir de um levantamento bibliográfico, comparando conceituações de pesquisadores da área, numa abordagem crítica. Como resultado destacamos que a biblioteca poderá ter seu espaço ampliado pela capacitação dos bibliotecários e usuários no manuseio dos Sistemas de Informação. O dinamismo do profissional bibliotecário seja como orientador no uso do Sistema de Informação, seja como executor da pesquisa, também é um minimizador das barreiras de usabilidade.

Palavras-chave: Sistemas de informação; Barreiras de usabilidade; Estudos de usuário

\section{INFORMATION SYSTEMS IN LIBRARIES: THE USERS AND LIBRARIANS' BEHAVIOUR IN FACE OF NEW INFORMATION TECHNOLOGIES}

\begin{abstract}
:
Information Technology influences the research and intellectual work in several areas of the knowledge. In libraries, technology is used by Information Systems in order to store, manipulate, filter and generate information through fast and efficient mechanisms. The present work intends to collaborate with the deepening of the knowledge concerning some fundamental questions of using Information Systems in libraries. It tries to understand and identify determinative aspects of the usability barriers that block the interaction user/system. Starting from a bibliographical research the study was conducted comparing conceptualizations of researchers of the area, in a critical approach. As a result, we point out that the library will be able to have its space extended through the librarians and users qualification to handle the Information Systems. The dynamism of the professional librarian acting both, as a guide to the Information System use and as a research executor, also minimize the usability barriers.
\end{abstract}

Key-words:

Information systems; Usability barriers; Users’ studies

\footnotetext{
${ }^{1}$ Artigo apresentado ao CURSO DE ESPECIALIZAÇÃO EM GESTÃO ESTRATÉGICA DE SISTEMA DE INFORMAÇÃO, do Departamento de Biblioteconomia do Centro de Ciências Sociais Aplicadas da Universidade Federal do Rio Grande do Norte, sob a orientação da Prof. ${ }^{a}$ Dr. ${ }^{a}$ Anatália Saraiva Martins Ramos como requisito parcial para o título de especialista.
}

(C) Revista Digital de Biblioteconomia e Ciência da Informação,Campinas, v.5, n. 2, p. 1-24, jan/jun. 2008- ISSN: 1678-765X. 


\section{INTRODUÇÃO}

O século XXI se inicia sob uma proposta de ampla conectividade, de preocupação com os conteúdos criados, manipulados e disseminados para os públicos mais diferenciados e heterogêneos, que chamamos de usuários (MARCHIORI, 2002, p. 72). A biblioteca, responsável pela criação e fornecimento de serviços e produtos de informação para os usuários (McGARRY, 1999, p. 122), mudou a forma de interação entre o profissional bibliotecário e o seu público, devido a essa nova proposta de conectividade.

Na biblioteca tradicional, o uso do papel como suporte de registro da informação é a característica principal. Na biblioteca conectada a sistemas de informação, a característica maior é armazenar a informação eletronicamente, disseminando-a independentemente de localização geográfica e física (RAMOS, 2003, p. 33). Vale ressaltar que o grande favorecido com a introdução dessas novas tecnologias, pelo menor tempo e custo na busca da informação, é o usuário.

O usuário pode utilizar o suporte tradicional ou digital da biblioteca para resolver seus problemas de busca de informação. Porém de nada adiantará os sistemas de informação e suas tecnologias, se o principal favorecido, o usuário, não souber ou não quiser interagir com a informação disponibilizada em meios eletrônicos, criando-se assim, as chamadas barreiras de usabilidade de sistemas de informação em bibliotecas.

Cabe ao profissional bibliotecário tornar claro o caminho do usuário, ou seja, todas as vias possíveis de acesso devem ser conhecidas, levando-o a entender o sistema de informação construído e minimizar as barreiras de usabilidade.

O presente trabalho abordará algumas questões fundamentais para o entendimento e a importância do uso de sistemas de informação em bibliotecas, buscando entender, através do conhecimento, o comportamento dos usuários desses sistemas.

Serão observadas as interações homem-máquina, bem como as barreiras de uso em Sistemas de Informação de bibliotecas. Tal estudo é justificado pela ausência do assunto nas publicações mais utilizadas em biblioteconomia.

(C) Revista Digital de Biblioteconomia e Ciência da Informação,Campinas, v.5, n. 2, p. 1-24, jan/jun. 2008- ISSN: 1678-765X. 


\section{INFORMAÇÃO E SOCIEDADE DA INFORMAÇÃO}

\subsection{O QUE É INFORMAÇÃO?}

Nunca se falou tanto em informação como nos dias de hoje, pois é impossível fazer parte da sociedade moderna e em constante mutação, sem se estar informado, e conseqüentemente sem conhecer os fatos que transformam nossas vidas. Segundo Dias et al (2004, p.2) a informação é matéria prima para que os indivíduos participem das mudanças na realidade social, organizacional e na sua própria realidade. A sociedade que tem acesso à informação pode tanto dominar setores como desenvolvê-los (ADRIANI; ZOMER apud PESTANA et al 2003, p. 77).

E o que vem a ser informação? Iniciaremos com uma definição não acadêmica para distinguirmos informação de dados, termos que são comumente confundidos, e posteriormente falar-se-ia do conceito de conhecimento.

Dado, por definição, é a informação em formato bruto, ou seja, o que não adquire sentido por si só, e conseqüentemente, não causa nenhuma transformação naquele que o recebe. Vejamos: imagine um usuário de biblioteca na busca de um determinado assunto que ele desconhece, para realização de uma prova. Ele só possui um dado, que é o assunto desconhecido, e automaticamente, por ser desconhecido, não lhe traz nenhuma transformação.

A informação é o dado já lapidado, isto é, com sentido, de modo que traga alguma mudança ao individuo que o adquiriu. Tendo por base o mesmo exemplo anterior, imagine uma nova situação: o usuário agora se dirige ao bibliotecário, que o auxilia na busca da informação, processando o dado informado, tratando-o, lapidando-o e, por conseguinte, tornando-o útil ao indivíduo. Quando são atribuídos aos dados valores, eles transformam-se em informação (REZENDE; ABREU, 2003, p. 90).

Finalmente conhecimento, é quando possuímos a informação e a utilizamos para um determinado propósito, colocando-a em prática. No nosso exemplo, seria afirmar que o usuário a utilizou na realização da prova. Conforme Jupiassú define (1996, p. 51), o conhecimento é uma apropriação intelectual de determinado campo, tendo em vista 
dominá-lo e utilizá-lo. Para Silva (2004, p. 144) uma informação é convertida em conhecimento quando um indivíduo consegue ligá-la a outras informações, avaliando-a e entendendo seu significado no interior de um contexto específico. Cabe ressaltar que o conhecimento não é estático, modificando-se mediante a interação com o ambiente, sendo esse processo denominado aprendizado (MORESI, 2000, p. 19).

Então podemos afirmar que a informação é o elo entre os dados não elaborados e o conhecimento adquirido. É afirmar que, informação é a ponte dessa tríade, onde se tem início com um simples dado, sendo a informação a força motriz para se atingir o conhecimento.

A informação é utilizada para aumentar o conhecimento do individuo, que pode aplicá-la em seu trabalho e modificar substancialmente o padrão de qualidade de vida de um país. Observa-se que a informação pode ser entendida como um recurso dissipador das incertezas (WETHERBE, 1987; CHIAVENATO, 1993 apud FERREIRA, 2003, p.36).

Diversos autores conceituaram o que viria a ser informação, porém o que se pode observar é que esses conceitos estão entrelaçados por várias definições. Para Stair e Reynolds (2002, p. 4) e O’Brien apud Silva (2003, p. 26) informação é uma coleção, conjunto de fatos ou dados organizados de modo que adquire um valor adicional além do valor dos próprios fatos, ou seja, quando um conjunto de dados é processado ou transformado, a fim de gerar resultados significativos e úteis, eles se tornam informação.

Machado (2003, p. 15) afirma que na linguagem comum, o conceito de informação está sempre ligado ao significado, sendo usado como sinônimo de mensagem, notícia, fatos e idéias que são adquiridos e passados adiante como conhecimento.

Para Epstein (1988) apud Stábile (2001, p. 55) a definição de informação apresentada é que informação é a redução de incertezas oferecida quando se tem uma pergunta.

Com Araújo (2002, p. 12) o conceito de informação pode ser buscado através da etimologia da palavra, que é de origem latina, do verbo informare, que significa dar forma, colocar em forma, criar, dar sentido.

Porém é no âmbito da Teoria da Informação, que se encontra o estudo da informação propriamente dito, introduzido por C. Shannon em 1948. Segundo Cohen (2002, p. 27), 
essa teoria foi alicerçada em um sistema de base matemática, onde seu objetivo principal era estudar os problemas de transmissão de mensagens, a partir de um emissor até o receptor. A informação, de acordo com essa teoria, depende de um processo de comunicação entre emissor-canal-receptor. Foi formalizada no inicio do século XX, e naquele momento o que preocupava era a quantidade de informação que um determinado canal suportava, a fim de corrigir e prever distorções na transmissão. O trabalho de C. Shannon se baseava num conjunto de teoremas, que buscava a maneira mais rápida, econômica e eficiente de enviar mensagens de um lugar para outro.

\subsection{POR QUE SOCIEDADE DA INFORMAÇÃO?}

Sabendo que a informação é o insumo básico para as atividades humanas (BRANDÃO, 2004, p. 2), e baseado nos conceitos colocados anteriormente, Araújo (2001) afirma que o poder de possuir vem sendo substituído pelo conhecimento, ou seja, a economia industrial está sendo substituída pela a economia da informação.

Conforme Toffler (1997) apud Silva (2003, p.18), o processo de desenvolvimento humano ocorre em ondas, que poderemos chamar de revoluções, sendo a primeira onda a agrícola, a segunda onda a industrial, caracterizada pela Revolução Industrial, e a terceira onda ou revolução, seria a tecnológica, onda que nos encontramos atualmente, marcada pela a importância da informação no contexto da globalidade em que vivemos. É nesse contexto que estamos vivendo, um momento de transição, de profundas mudanças e transformações, na qual se opera a mais radical das revoluções existentes. O produto do agora é a informação e o elemento fundamental desse produto é o ser humano. (ARAÚJO, 2001).

Por esse motivo é que se diz que estamos vivendo em plena terceira revolução, a Revolução da Informação, ou na Sociedade da Informação. E o que vem a ser a Sociedade da Informação? Quais as mudanças observadas?

Segundo Oliveira (2004, p. 36) a Sociedade da Informação é uma complexa rede profissionalizada de produção e uso da informação. É usar conhecimento para gerar conhecimento, deixando de ser, a informação, um fenômeno espontâneo e em grupos isolados, para ser um fenômeno global. Essa sociedade não é caracterizada por um 
modismo e sim por mudanças, onde a informação disponível afetará a dinâmica nessa sociedade.

Podemos caracterizar como uma mudança significativa, o fato que a Sociedade da Informação vive pela informação, sendo possível observar, que se consome informação na embalagem, no design e principalmente vai-se ao consumo pela informação. Conforme Santos (2004, p.11; 23) é o pós-modernismo, que invadiu nosso cotidiano, visando à sua saturação com informações, coisa típica das sociedades pós-industriais baseadas na informação. Pode-se afirmar que a Sociedade da Informação é pósmodernista, mobilizada pela a informação e o consumo.

\section{TECNOLOGIA NA SOCIEDADE: EVOLUÇÃO E CONCEITO}

A sociedade hoje vive com dois grandes problemas relacionados com a informação: a grande quantidade gerada e a necessidade de controlá-la. Afirma Machado (2003, p.71) que o cérebro humano não suporta o peso desse conhecimento acumulado e registrado em diferentes suportes.

Segundo Cruz (2003, p. 47) a humanidade tem seu progresso baseado em pesquisa, estudo e investigação, que geram saber, conhecimento ou, simplesmente, informação. Conforme Silva (2003, p. 21) a globalização demanda organização, agilidade e precisão nas atividades desempenhadas.

A utilização do computador para ordenar a informação gerada e registrada, foi a grande resposta à explosão do novo século. A era da informática é o tratamento computadorizado do conhecimento e da informação.

O surgimento da tecnologia se deu no período da Revolução Industrial, com a evolução das técnicas empregadas na época, impulsionada pela competição e pela necessidade de criação de novos produtos (GARCIA, 2001). Podemos afirmar que segundo Garcia (2001) a tecnologia foi diretamente relacionada com as inovações humanas, que se faziam necessárias, para o desenvolvimento a partir da era moderna. Pode-se definir tecnologia também como a aplicação das descobertas da ciência aos objetivos da vida prática. (LIMA; MENDES, 2003).

(C) Revista Digital de Biblioteconomia e Ciência da Informação,Campinas, v.5, n. 2, p. 1-24, jan/jun. 2008- ISSN: 1678-765X. 
A tecnologia de informação é a utilização de recursos tecnológicos e computacionais para geração e disseminação da informação. Os componentes que interagem e complementam esse conceito são: a) hardware (computador e seus periféricos, como por exemplo, o mouse, impressora, etc); b) software (programas de computador); c) sistemas de comunicação (que é a transmissão de sinais de um emissor para um receptor, ou seja, as redes de dados); d) organização das informações (o sistema de informação propriamente dito).

Não se pode negar que a tecnologia trouxe inúmeros benefícios para o homem, dos quais o principal foi tornar o trabalho mais fácil e mais produtivo. Vale ressaltar que não são necessários conhecimentos profundos para manipular essa nova tecnologia, e que a tecnologia de informação é muito mais que máquinas e equipamentos, pois envolve também as pessoas, é um conjunto de conhecimento técnico e empírico.

A palavra tecnologia é de origem grega, vem do termo "techne": artefato, originalmente algo simplesmente esculpido, e "logos": pensamento ou razão, isto é, o estudo de algo.

\subsection{TECNOLOGIA DA INFORMAÇÃO EM BIBLIOTECAS}

Segundo Oliveira (2002, p. 10) as bibliotecas têm passado por períodos marcantes de transição. Com o advento da imprensa, no início do século XV, foi concebida a ela uma nova função, além da de organizadora dos saberes, a de sistematizar o acesso à informação, passando a atuar como centros de educação, recreação e pesquisa. O segundo momento surgiu com os computadores, que conquistaram todos os campos de atividade. O terceiro período de transição tem se caracterizado pelas soluções qualitativas, que implicam em redução de tempo e de precisão dos serviços. Disponibilizar dados de forma rápida e eficaz, ou seja, quanto mais o homem gera documentos, mais as bibliotecas buscam instrumentos e técnicas que permitam a recuperação desses documentos, a informação tornou-se um bem acumulável e valorável (MILANESI, 1983, p.22).

Nos pilares da chamada Sociedade da Informação, está a tecnologia (DAVENPORT, 1998 apud FERREIRA, 2003, 45). Segundo Pereira (1999) apud Ramos (2003, p. 15), a união das palavras "tecnologia e informação" começou a ser empregada na década de 
80, para explicar a convergência de diversas correntes de desenvolvimento tecnológico, principalmente àquelas associadas à microeletrônica, às telecomunicações e à informática.

ALBERTIN apud STÉBILE (2001, p. 61) afirma que o conceito de tecnologia da informação é bastante abrangente, porém a definição que considera a mais adequada é que a tecnologia da informação é tudo aquilo com que se pode obter, armazenar, tratar, comunicar e disponibilizar informação digitalizada.

O impacto causado nas bibliotecas, com a introdução das tecnologias da informação foram às novas maneiras de interação entre seus profissionais e seus usuários (RAMOS, 2003, p. 21). Hoje as bibliotecas são reconhecidas como espaços informativos, para conhecer, discutir, criar e recriar. O acervo é planetário e acessível no intangível formato eletrônico, rapidamente repensado à velocidade da tecnologia. Segundo Milanesi (1983, p. 9), quanto mais uma biblioteca propicia uma multiciplidade de informações, mais ela estará chegando ao seu objetivo.

Machado (2003, p. 75) diz que a aplicação da informática nesse processo de crescimento da informação foi o grande propulsor do surgimento de sistemas de informação em bibliotecas. As novas tecnologias implementadas em bibliotecas, poderoso instrumento de comunicação que diminui as distâncias, fizeram com que as mesmas rompessem com o modelo tradicional: o acervo físico. Para Cuenca e Tanaka (2003) a tecnologia da informação tem seu maior produto na Internet, considerado um poderoso instrumento de comunicação.

Os grandes benefícios que as tecnologias de informação proporcionam às bibliotecas são: racionalidade no trabalho, aumento de produção, melhor controle e uma maior facilidade de armazenamento e disseminação da informação (RAMOS, 2003, p. 35).

Oliveira (1996) apud Ramos (2003, p.15), explica que três grupos de modificações foram passíveis no ambiente das bibliotecas.

a) O primeiro grupo, diz respeito à produção física e à produção da informação e do conhecimento; 
b) O segundo grupo, refere-se aos trabalhos de coordenação, onde as tecnologias são o objeto fundamental da mudança. À medida que a distância física é menor, o tempo de transmissão da informação se reduz e, a memória da biblioteca pode ser conservada em banco de dados, tornando possível uma maior flexibilidade e concedendo à biblioteca, uma melhor utilização das habilidades existentes;

c) O terceiro grupo diz respeito à gestão, intervindo tanto na direção como no controle e monitoramento da mesma, em seu meio; o controle do desempenho conserva-se na direção desejada e planejada, possibilitando uma tomada de decisão mais eficaz e rápida, tornando as bibliotecas mais flexíveis. Essas transformações abalaram tanto a estrutura das bibliotecas, seus usuários, bem como, seus bibliotecários.

\section{TEORIA GERAL DOS SISTEMAS}

A origem dos sistemas se deu em 1950, sob o impulso do biólogo alemão Ludwig von Bertalanffy, com a chamada Teoria Geral dos Sistemas. Bertalanffy pesquisando sobre o comportamento dos organismos vivos, constatou que, mesmo com as variedades de formas e características, eles possuíam pontos em comum (REZENDE, 2003, p. 28; OLIVEIRA, 2004, p.64; STAIR, 2002, 7).

A Teoria Geral dos Sistemas fundamenta-se em três premissas básicas:

1. Os sistemas existem dentro dos sistemas - Porque as moléculas estão dentro das células, às células dentro dos tecidos, os tecidos dentro dos órgãos e assim por diante;

2. Os sistemas são abertos - Porque é uma decorrência da premissa anterior, caracterizada por um processo de intercâmbio infinito com seu ambiente, que são os outros sistemas; 
3. E as funções de um sistema dependem de sua estrutura - Porque os sistemas são interdependentes, à medida que suas funções se contraem ou expandem, sua estrutura acompanha.

Nesse contexto, sistema é entendido como um conjunto de partes que se relacionam, cujos objetivos fazem com que o arranjo das partes não ocorra ao acaso (GUIMARÃES; ÉVORA, 2004, p. 73).

Em sentido geral, sistema significa, segundo Japiassú (1996, p. 249), Doron e Parot (1998, p. 713), um conjunto de elementos ou partes interdependentes que constituem uma totalidade organizada, de acordo com determinados princípios. Podemos considerar que um sistema é basicamente um conjunto de elementos ou componentes em interação para cumprimento de metas (STAIR; REYNOLDS, 2002, p. 7).

Segundo Rezende (2003, p. 33) a composição moderna dos sistemas ultrapassa a convenção simplória e antiga: entrada - processamento - saída. Os sistemas hoje são compostos basicamente por: objetivos - entradas - transformações - saídas - feedback.

a) Os objetivos - É a razão de existir do sistema, a finalidade para a qual o sistema foi criado;

b) As entradas - Sua função é fornecer ao sistema o material para a operação que gerará as saídas, esta deverá está em sintonia com os objetivos do sistema;

c) As transformações - Esse processador é a maneira pela qual os componentes interagem no sentido de produzir saídas desejadas. É nessa etapa que o insumo (entradas) se transforma em produto (saídas);

d) As saídas - Correspondem aos resultados do processo de transformação, devem ser coerentes com os objetivos do sistema;

e) O feedback - É considerado sinalizador e regulador dos mecanismos de entrada, transformação e saída do sistema. É utilizado para fazer ajustes ou modificações nas atividades do sistema. 
Exemplificando de forma clara e objetiva o que viria a ser a composição moderna de um sistema, vamos considerar um lava-jato, onde seu objetivo principal seria a lavagem do carro de forma rápida; as entradas tangíveis para o processo são: um carro sujo, a água e os ingredientes de limpeza, tempo, energia, entre outras; as transformações consistiriam em selecionar as opções de limpeza, se com lavagem simples ou completa, etc.; a saída é um carro limpo e finalmente a avaliação do cliente quanto à limpeza do carro denominaríamos como o mecanismo de feedback (STAIR; REYNOLDS, 2002, p. 8).

\section{SISTEMAS DE INFORMAÇÃO}

Como o próprio nome diz: sistema de informação é um sistema baseado em informações, ou seja, a sua matéria prima é a informação. O sistema de informação pode ser tecnicamente definido como um conjunto de componentes inter-relacionados que coleciona ou recupera, processa e distribui informação. Porém o que precisamos entender é como se dá o comportamento coletivo desses componentes.

Vale salientar que um sistema de informação pode ser manual ou computadorizado (RAMOS, 2004, p. 17). Nos dois casos previstos: manual ou computadorizado, há o elemento indispensável que são as pessoas, pois são elas que concebem, programam, gerenciam, executam e mantêm o sistema, sendo a partir daí que existirá a seleção e a organização das informações para a sua efetiva utilização.

Com relação aos sistemas de informação computadorizados, é importante perceber que o fato de se espalhar computadores em toda a empresa (Bibliotecas, Centro de Documentação, Instituições, etc), ligando-os em redes e instalando sistemas aplicativos, não irá organizar a mesma.

Quando as informações estão organizadas e planejadas nos sistemas de informação, estes geram informações eficientes e eficazes para atender à demanda e antecipar as necessidades dos usuários desse sistema, desencadeando um processo de conhecimento. Os cérebros automatizados poderão organizar essas informações e torná-la viável ao cérebro humano. 
Uma das principais funções dos sistemas de informação é a de filtrar a informação para gerar conhecimento. Por isso, conforme Ferreira (2003, p.36), cada vez mais, grandes corporações vêm realizando investimentos vultosos em sistemas de informação, objetivando interagir de forma mais rápida e dinâmica em diversas áreas estratégicas.

Os sistemas de informação devem trazer informações de qualidade, embora sabermos da existência de alguns sistemas de desinformação, dando conotação negativa à informação, ou seja, manipulando e produzindo desinformação. E por que isso acontece? Porque as pessoas envolvidas nesse processo, que são as fontes de entradas de informações, acabam introduzindo informações equivocadas, que geram saídas inadequadas.

Algumas das características do sistema de informação é que ele deve ser fácil de usar, flexível nos ajustamentos, confiável nas informações geradas e rentáveis de modo que os custos justifiquem os benefícios oferecidos.

Baseada nas considerações acima se pode chegar a conclusão que um sistema de informação é aquele que manipula e gera informação, usando ou não recurso tecnológico, com o objetivo de auxiliar na tomada de decisão, permitindo a comunicação entre emissor e receptor.

Os benefícios e uso dos sistemas de informação ajudam tanto em termos pessoais como profissionais. Todo sistema tem algum grau de relacionamento e de dependência com o ambiente, pois qualquer atividade desempenhada por um sistema de informação pode ser desempenhada manualmente, porém o tempo gasto seria proibitivo ao trabalho manual.

\section{COMPORTAMENTO DOS USUÁRIOS DE BIBLIOTECAS EM SISTEMAS DE INFORMAÇÃO}

Inicialmente falamos em informação, e da importância de se estar informado. Hoje vivemos em uma verdadeira enxurrada de informações, que para ser eficiente e eficaz, precisa está organizada e disponibilizada em meios acessíveis. Daí surge a tecnologia da informação, que nasce com a Sociedade da Informação estabelecendo seus pilares no uso massificado da informação para gerar conhecimento.

(C) Revista Digital de Biblioteconomia e Ciência da Informação,Campinas, v.5, n. 2, p. 1-24, jan/jun. 2008- ISSN: 1678-765X. 
Mudar faz parte da natureza, sendo assim, as novas tecnologias da informação não poderiam deixar de se incorporarem aos processos das bibliotecas modernas através dos sistemas de informação. As mudanças, em muitos casos, significam inovar ou antecipar e, portanto, aceitar os ajustes, adaptar-se ou renovar-se. Porém essas mudanças são mais dolorosas para uns que para outros. E para que essa mudança não seja tão traumática, o que se deve fazer primeiro é conscientizar os usuários dos benefícios do uso do sistema e em seguida desenvolver cursos de curto prazo e específicos, afim de que os principais beneficiários, os usuário, tenham familiaridade com o sistema.

Os sistemas de informação em bibliotecas surgiram com a intenção de auxiliar os usuários na difícil tarefa de recuperar informação. As funções de tais sistemas já foram faladas anteriormente, porém é na classificação e interação desses usuários que iremos nos deter agora.

Tendo em vista que cada vez mais os sistemas de informação estão presentes em nossas bibliotecas, é importante treinamentos para a aceitação e a implementação de novas políticas nas bibliotecas (STAIR; REYNOLDS, 2002, p. 444). Apesar de muitas bibliotecas já possuírem em seus procedimentos treinamentos com seu público-alvo, ainda não é o suficiente para que os usuários sintam-se confortáveis na busca da informação desejada através da tecnologia.

Para podermos identificar quais as dificuldades encontradas na interação usuário/sistemas, resolvemos classificar os usuários da seguinte maneira: os considerados principiantes, que são os que merecem maior atenção e acompanhamento dos bibliotecários; e um outro grupo, que são os instruídos, nesse a contribuição é significativa nas atividades de inovação e planejamento do sistema.

Mas por que usuários, de um modo geral, principiantes e instruídos, ainda não se sentem confortáveis na busca pela informação desejada através dos sistemas de informação? Afirma Figueiredo (1987, p. 78) que os usuários de sistemas de informação têm reagido como qualquer pessoa que tem que se defrontar com uma nova idéia. Na verdade o que os usuários realmente querem é que suas expectativas de informação sejam atendidas, não importando o formato de recuperação da pesquisa e nem quem a executa, segundo Garcez e Rados (2002, p. 46). 


\subsection{COMPORTAMENTO USUÁRIOS VERSUS SISTEMAS DE INFORMAÇÃO}

As relações homem-computador têm sido objeto de profundas reflexões e estudos em função das novas tecnologias para processamento e disseminação da informação e de sua influência no comportamento da sociedade em que vivemos, é o que afirma Heemann (1997).

Os sistemas de informação, em sua maioria, foram desenvolvidos, ao longo do tempo, sempre com as atenções voltadas às tecnologias empregadas e não ao uso estratégico ou à adequação aos usuários (STÉBILE, 2001, p. 163). Os processos de criação dos sistemas devem ser centradas nos usuários, sua interface deve ser projetada como objetivo de satisfazer as necessidades dos usuários.

Para Oliveira (2004, p. 120) os sistemas que tendem a incomodar ou frustrar os usuários não podem ser sistemas eficazes, seja qual for seu grau de elegância técnica e de eficácia no processamento de dados. Como exemplo, poderíamos citar Machado (2003, p.147) que se refere à quantidade de referências bibliográficas resgatadas em uma busca no sistema, que muitas vezes excede as possibilidades do usuário de convertê-la em informação.

Já foi dito que as inovações tecnológicas nas bibliotecas produzem transformações profundas na vida cotidiana dos usuários. O fato de se dar mais atenção aos computadores (software) e na pouca atenção dada aos seres humanos (usuários), nos aponta para problemas na interação usuários versus sistemas e na subutilização dessas tecnologias (AGNER, 2004).

Esses desperdícios e erros, na arquitetura dos sistemas, não são os únicos causadores das barreiras de usabilidade em sistemas de informação. O comportamento dos usuários também contribui com uma parcela significativa nesse processo de interação. Segundo Rezende e Abreu (2003, p. 119) os hábitos individuais são outra forma de bloqueio à inovação. 
E que barreiras de usabilidade são essas relacionadas aos usuários e aos sistemas de bibliotecas? Em primeiro lugar deveremos falar um pouco da questão de usabilidade, para que se possam entender as barreiras.

Usabilidade é a característica que determina se o manuseio de um produto é fácil e rapidamente aprendido, com quantidade pequena de erros operacionais e oferecimento de um alto grau de satisfação, atingindo seus objetivos. (LIRA, 2005; FERREIRA; LEITE, 2003, p. 117). O conceito não é novo e sua origem está ligada à ergonomia.

Quais as características que um sistema de informação deverá possuir para ter usabilidade? Segundo Dias (2003) apud Vidotti e Sanche (2004, p. 4):

1. Eficácia e eficiência de uso - o sistema deve ser eficiente a tal ponto de permitir que o usuário tendo aprendido a interagir com ele, atinja níveis altos de produtividade na realização de suas tarefas;

2. Satisfação subjetiva - o usuário considera agradável à interação com o sistema e se sente subjetivamente satisfeito com ele;

3. Facilidade de aprendizado - o sistema deve ser fácil de aprender, de tal forma que o usuário consiga rapidamente explorá-lo e realizar suas tarefas com ele. Em geral, um sistema é considerado de fácil aprendizado quando usuários inexperientes conseguem atingir um certo grau de proficiência em um curto período de tempo;

4. Facilidade de memorização - após um certo período sem utilizá-lo, o usuário não freqüente é capaz de retornar ao sistema e realizar suas tarefas sem a necessidade de reaprender como interagir com ele;

5. Baixa taxa de erros - em um sistema com baixa taxa de erros, o usuário é capaz de realizar tarefas sem maiores transtornos, recuperando erros, caso ocorram; 
6. Consistência - tarefas similares requer seqüências de ações similares, assim como ações iguais devem acarretar efeitos iguais. Usar terminologia, leiaute gráfico, conjuntos de cores e de fontes padronizados também são medidas de consistência;

7. Flexibilidade ou feedback - refere-se à variedade de formas com que o usuário e o sistema trocam informações. Este atributo diz respeito à capacidade do sistema em se adaptar ao contexto e às necessidades e preferências do usuário, tornando seu uso mais eficiente. Em função da diversidade de tipos de usuários de um sistema interativo, é necessário que sua interface seja flexível o bastante para realizar a mesma tarefa de diferentes maneiras, de acordo com o contexto e com as características de cada tipo de usuário.

No universo específico dos sistemas de informação, existem muitas teorias utilizadas para estudar a aceitação e o comportamento dos usuários de tecnologia da informação, porém o que é importante saber é se os usuários usam o sistema, como, porque e quando o usam.

Os estudos em cima da questão de usabilidade em sistemas começaram a partir da década de 80, por Fred D. Davis (1989, p. 321), pesquisador em sistemas de informação. Davis propôs um modelo que auxiliasse e previsse o uso dos sistemas, desenvolvendo o Technology Acceptance Model - TAM, modelo de aceitação de tecnologia, como afirma Bueno et al (2004).

O ponto principal de usabilidade é levar em consideração que em todo manuseio homemmáquina deve haver interação (FERREIRA; LEITE, 2003, p. 116).

Segundo Dias et al (2003b, p. 16) alguns autores abordam o comportamento dos usuários com relação à não aceitação da tecnologia como uma questão de resistência às mudanças, sem entender, contudo os motivos de tal resistência. A seguir algumas barreiras mencionadas na literatura com relação à usabilidade em sistemas de informação:

Barreiras Socioeconômicas - A miséria talvez seja a pior das nossas mazelas, e a reprodução da miséria se dá com a combinação de três elementos: a falta de crédito, a deficiência educacional e a carência de tecnologia (SANTOS, 2002-2005). Compreende- 
se aqui o outro lado da Sociedade da Informação que é a Sociedade da Desinformação, do analfabetismo tecnológico. O Governo deve promover a universalização do acesso e uso dos meios eletrônicos de informação, a chamada alfabetização digital (TAKAHASHI, 2000, p. 5;33). Caso contrário, a população com escassos recursos financeiros, não poderão usufruir os benefícios tecnológicos.

Barreiras Tecnológicas - Aqui poderemos citar a chamada lei do menor esforço ou princípio do menor esforço, que estabelece que nenhum sistema de informação é utilizado se não for de fácil acesso e de facilidade de uso (FIGUEIREDO, 1987, p. 76). Essa lei tem duas faces: uma é o fato do sistema não ser acessível, como já foi mencionado, e a outra diz respeito ao comodismo dos usuários, que preferem que suas consultas sejam feitas pelo profissional bibliotecário, sem seque tentar uma aproximação com o sistema.

Barreiras Psicológicas - Dizem respeito ao próprio usuário, como afirma Figueiredo (1987, p.76), esse usuário pode trazer a sua própria autopercepção dos serviços e produtos - se o usuário acredita que o sistema é eficiente, então para ele o sistema é eficiente, e o oposto é também verdadeiro. Traz preconceitos e comportamentos pessoais na busca pela informação e essa reação, segundo Rezende e Abreu (2003, p.119) geralmente vem acompanhada pela inabilidade de acompanhar as mudanças causadas pelo computador de modo saudável, e a cyberphobia, que é o medo do computador e de coisas ligadas a ele.

Barreiras Institucionais - Segundo Figueiredo (2003, p. 77) são aquelas criadas ou existentes no próprio sistema, tais como: coleções deficientes e defasadas, sistema sem manutenção técnica, normas restritas ao uso, pessoal sem treinamento apropriado.

\subsection{CAPACITAÇÃO NO USO DE SISTEMAS DE INFORMAÇÃO}

Segundo McGarry (1999, p.111) há muito tempo na história intelectual descobrimos uma forte e mutuamente sustentável relação entre informação e poder sobre os outros, que não implica privar alguém dos frutos ilimitados do intelecto humano. Pensando assim, o levantamento das necessidades de capacitação em sistemas de informação, para ser feita de forma eficiente deverá ser centrada na seguinte questão: quem necessita?

(C) Revista Digital de Biblioteconomia e Ciência da Informação,Campinas, v.5, n. 2, p. 1-24, jan/jun. 2008- ISSN: 1678-765X. 
Respondendo a indagação poderíamos afirmar que um dos objetivos específicos dos sistemas de informação é minimizar o tempo de buscar do usuário numa determinada pesquisa, conforme Garcez e Rados (2002, p. 50) a formulação dessa estratégica de busca deve requerer conhecimento do assunto pesquisado, do sistema e da bibliografia, portanto deve ser feita pelo usuário ou bibliotecário. Então a necessidade de capacitação é bilateral, tanto o usuário, quanto o bibliotecário, devem estar em sintonia com o sistema de informação, a fim de que haja a eficácia e eficiência de uso.

A pesquisa em sistema de informação busca a criatividade de quem a executa. O primeiro passo é definir o que se procura, seguido de como procurar, selecionando o que interessa e posteriormente combinar esses dados para se atingir o objetivo esperado. A busca em um sistema levará o usuário a um conjunto de conflitos e reforços de informações, muito mais de reforços, onde abrirá um leque de oportunidades de dados para se atingir ao conhecimento. Cabe ao bibliotecário também saber usar para orientar. Para Jambeiro e Silva (2004) o pesquisador/usuário ganhou uma autonomia, um self service informacional: quem precisa pega sem esperar ser servido, objetivo maior da capacitação.

\section{CONSIDERAÇÕES FINAIS}

A tecnologia influencia o trabalho intelectual e de pesquisa nas várias áreas do conhecimento, modificando as relações econômicas, políticas, culturais entre os grupos sociais.

O homem criou a escrita e financiou uma guerra no processo de comunicação, novas tecnologias de comunicação surgiram e as já existentes se aperfeiçoaram. Hoje não mais importa onde a informação se encontra e sim a forma de aceso a essa informação.

Como foi observado ao longo do texto, enfatizou-se a importância da informação em nossa sociedade, o ritmo acelerado da produção, bem como o acúmulo desordenado da mesma. Com o advento da tecnologia da informação, que veio para racionalizar a enxurrada de informações com a criação dos sistemas, desenvolveram-se novos métodos computacionais de armazenamento, organização e disseminação dessa informação.

(C) Revista Digital de Biblioteconomia e Ciência da Informação,Campinas, v.5, n. 2, p. 1-24, jan/jun. 2008- ISSN: 1678-765X. 
Segundo Cruz et al (2003, p. 47) com o surgimento da tecnologia da informação, a massa informacional deverá ser armazenada com ordem, de forma que nos seja especificados satisfatoriamente, os meios de disseminar os conteúdos dessas informações, caso contrário, seremos esmagados sobre o peso do dilúvio informacional.

As mudanças que as bibliotecas passaram e vem passando ao longo do tempo com as inovações tecnológicas, exigindo das mesmas, implantação de novas infra-estruturas compatíveis com a demanda crescente de informações. O usuário, razão de ser da biblioteca, logo sentiu as transformações impostas pela tecnologia da informação. As barreiras comportamentais que essas inovações tecnológicas causaram, fossem elas de ordem tecnológica, psicológica, socioeconômica e/ou institucional, se refletiram diretamente no uso e na busca de informação através dos sistemas de informação utilizados nas bibliotecas.

Não se tem nenhuma dúvida que a capacitação dos usuários no manuseio dos sistemas de informação em bibliotecas é extremamente importante e necessária. Pois é, a partir dessa intimidade com o sistema que o usuário descobrirá novas informações, além daquelas que ele deseja, e lhe dará várias oportunidades de novos conhecimentos.

A biblioteca poderá ter sua função e espaço ampliado pelo dinamismo do profissional bibliotecário, seja como orientador no uso do sistema de informação, seja como executor da pesquisa. Para Tarapanoff et al (2002) apud Miranda (2004, p. 118), os cientistas da informação devem ser mediadores entre o mundo digital e a capacidade real de entendimento do receptor da informação, garantindo a efetiva comunicação e a satisfação da necessidade informacional do usuário dessa tecnologia. Cunha (2003, p. 3) acrescenta que o profissional da informação é um ser essencialmente social, um ser de mediação e contato, de fazer com o outro e de fazer para o outro.

Não devemos esquecer que paralela à Sociedade da Informação, àquela onde há usuários capazes trafegar pelas infovias, tendo total autonomia na busca de seus próprios caminhos, definindo os atalhos preferidos, há também a Sociedade da Desinformação, uma sociedade de maior proporção, a sociedade do analfabetismo digital e dos excluídos tecnológicos, onde a figura do profissional da informação deverá ocupar um importante espaço entre o hiato existente das duas sociedades, sendo o ponto de interseção. 


\section{REFERÊNCIAS}

AGNER, Luiz. Arquitetura de informação: testes de usabilidade. 2004. Disponível em: < http://webinsider.uol.com.br/index.php/2004/01/06/arquitetura-de-informacao-testes-deusabilidade/ > . Acesso em: 15. fev. 2005.

ARAÚJO, Andréa Cristina Marques de. A informação como fator diferenciador para o sucesso estratégico das organizações. 2001. Disponível em: <

http://www.informal.com.br/pls/portal/docs/PAGE/GESTAODOCONHECIMENTOINFORMALI NFORMATICA/ARTIGOSGESTAODOCONHECIMENTO/ARTIGOSGC/ARTIGO_100902.PD F> . Acesso em: 15. fev. 2005.

ARAUJO, Eliany Alvarenga de. O fenômeno informacional na ciência da informação: abordagem teórica-conceitual. In: CASTRO, Cesar. Ciência da informação e biblioteconomia: múltiplos discursos. São Luiz, 2002. p. 11-34.

ARELLANO, Miguel Angel Márdero. Serviço de referência virtual. Ci. Inf., Brasília,v. 30, n. 2, p. 7-15, mai./ago. 2001.

BRANDÃO, Wladmir C. A internet como fonte de informação para negócios: um ensaio sobre a realidade da internet brasileira. Perspectiva em Ciência da Informação, Belo Horizonte, v. 9, n.1, p. 88-99, jan./jul. 2004.

BUENO, Ubiratan et al. Um estudo comparativo do modelo de aceitação de tecnologia aplicado em sistemas de informações e comércio eletrônico. In: CONGRESSO INTERNACIONAL DE GESTÃO DE TECNOLOGIA E SISTEMAS DE INFORMAÇÃO, 1., 2004. São Paulo, SP. Anais do $1^{\circ}$ CONTECSI. São Paulo: [s.n], 2004.

CASTRO, César Augusto, RIBEIRO, Maria Solange Pereira. As contradições da sociedade da informação e a formação do bibliotecário. Revista Digital de Biblioteconomia e Ciência da Informação, Campinas, v. 1, n. 2, p. 41-52, jan./jun. 2004.

COHEN, Max F. Alguns aspectos do uso da informação na economia da informação. Ci. Inf., Brasília, v. 31, n. 3, p. 26-36, set./dez. 2002.

CRUZ, Angelo Antonio Alves Correa; BATTAGLIA, Beatriz Bergonzoni; Oliveira, Érica Beatriz Pinto Moreschi et al. Impacto dos periódicos eletrônicos em bibliotecas universitárias. Ci. Inf., Brasília, v. 32, n. 2, p. 47-53, mai./ago. 2003.

CUENCA, Angela Maria Belloni; TANAKA, Ana Cristina D`Andretta. As novas tecnologias na comunicação científica: o uso da internet pela comunidade de docentes da área de saúde pública. 2003. Disponível em: <http://www.sibi.usp.br/sibi/boletim_inter/vol_8_num_6/Angela.pdf>. Acesso em: 31. ago. 2005.

CUNHA, Miriam Vieira da. O papel social do bibliotecário. Enc. Bibli: R. Eletr. Bibliotecon. Ci. Inf., Florianópolis, n. 15, p. 1-6, 2003. 
DAVENPORT, Thomas H. Ecologia da Informação: por que só a tecnologia não basta para o sucesso na era da informação. 5. ed. Tradução Bernadete Siqueira Abrão. São Paulo: Futura, 1998. 316 p. Tradução de: Information ecology.

DAVIS, Fred D. Perceived usefulness, perceived ease of use and user acepptance of information technology. Mis Quarterly, v. 13, n. 3, p. 319-340, 1989.

DIAS, Maria Matilde Kronka et al. Capacitação do bibliotecário como mediador do aprendizado no uso de fontes de informação. Revista Digital de Biblioteconomia e Ciência da Informação, Campinas, v. 2, n. 1, p.1-16, jul./dez. 2004. Disponível em:

$<$ http://server01.bc.unicamp.br/seer/ojs/viewarticle.php?id=22\&layout=abstract $>$. Acesso em: 15. mai. 2005.

DIAS, Raquel. O comportamento do consumidor de informações. RESI - Revista Eletrônica de Sistemas de Informação, Paraná, Ano 2, v. 2, n. 1, jul. 2003a. Disponível em:

<http://www.inf.ufsc.br/resi/edicao02/artigo04.pdf>. Acesso em: 15. mai. 2005.

DIAS, Marcelo Capre et al. Análise do modelo de aceitação de tecnologia de Davis. R. Spei, Curitiba, v. 4, n. 2, p. 15-23, jul./dez. 2003b.

DORON, Roland; PAROT, Françoise. Dicionário de psicologia. Tradução Odilon Soares Leme. São Paulo: Ática, 1998. 863 p. Tradução de: Dictionnaire de psychologie.

FERREIRA, Danielle Thiago. Profissional da informação: perfil de habilidades demandadas pelo mercado de trabalho. Ci. Inf., Brasília, v. 32, n. 1, p. 42-49, jan./abr. 2003.

FERREIRA, Rubens da Silva. A sociedade da informação no Brasil: um ensaio sobre os desafios do Estado. Ci. Inf., Brasília, v. 32, n. 1, p. 36-41, jan./abr. 2003.

FERREIRA, Simone Bacellar Leal; LEITE, Julio César Sampaio do Prado. Avaliação da usabilidade em sistemas de informação: o caso do sistema submarino. RAC - Revista de Administração Contemporânea, v. 7, n. 2, p. 115-136, abr./jun. 2003.

FIGUEIREDO, Nice Menezes. Da necessidade de promover o uso da informação. Ci. Inf., Brasília, v. 6, n. 1, p. 75-79, jan./jun. 1987.

GARCIA, Joana Coeli Ribeiro. Transmissão de tecnologia: análise do conceito. DataGramaZero Revista de Ciência da Informação, Rio de Janeiro, v. 2, n. 2, abr. 2001. Disponível em:

<http://www.dgz.org.br/abr01/F_I_art.htm>. Acesso em: 15. ago. 2005.

GUIMARÃES, Eliane Marina Palhares; ÉVORA, Yolanda Dora Martinez. Sistema de informação: instrumento para tomada de decisão no exercício da gerência. Ci. Inf., Brasília, v. 33, n. 1, p. 72-80, jan./abr. 2004.

HEEMANN, Vivian. Avaliação ergonômica de interfaces de bases de dados por meio de checklist especializado. 1997. Dissertação (Mestrado em Engenharia de Produção) - Universidade Federal de Santa Catarina, Florianópolis, 1997. Disponível em:

<http://www.eps.ufsc.br/disserta97/heemann/>. Acesso em: 15. mai. 2005.

HONG, Weiyin et al. Determinants of user acceptance of digital libraries: an empirical examination of individual differces and system characteristics. Journal of Management Information Systems, 
v. 18, n. 3, p. 97-124, 2002. Disponível em: <http://jmis.bentley.edu/articles/v18_n3_p97/>. Acesso em: 30. ago. 2005.

JAMBEIRO, Othon; SILVA, Helena Pereira da. A informação e suas profissões: a sobrevivência ao alcance de todos. DataGramaZero - Revista de Ciência da Informação, Rio de Janeiro, v. 5, n. 4, ago. 2004. Disponível em: <http://www.dgz.org.br/ago04/Art_03.htm>. Acesso em: 15. mai. 2005.

JAPIASSÚ, Hilton; MARCONDES, Danilo. Dicionário básico de filosofia. 3. ed. Rio de Janeiro: Jorge Zahar, 2001. 296 p.

LIMA, Marcos Antonio Martins; MENDES, José Piragibe Figueiredo. Inovação na gestão organizacional e tecnológica: conceitos, evolução histórica e implicações para as micros, pequenas e médias empresas no Brasil. Revista cientifica eletrônica de engenharia de produção, v. 3, n. 2, jun. 2003. Disponível em: <http://www.producaoonline.ufsc.br/v03n02/artigos.php>. Acesso em: 15. ago. 2005.

LIRA, Márcia. Você já ouviu falar no termo usabilidade? Diário de Pernambuco, Recife, 13 abr. 2005. Caderno de Informática. Disponível em:

<http://www.pernambuco.com/diario/2005/04/13/info11_0.asp>. Acesso em: 13. abr. 2005.

MACHADO, Ana Maria Nogueira. Informação e controle bibliográfico: um olhar sobre a cibernética. São Paulo: UNESP, 2003. 159 p.

MARCHIORI, Patrícia Zeni. A ciência e a gestão da informação: compatibilidade no espaço profissional. Ci. Inf., Brasília, v. 31, n. 2, p. 72-79, mai./ago. 2002.

McGARRY, Kevin. O contexto dinâmico da informação: uma análise introdutória. Tradução Helena Vilar de Lemos. Brasília: Briquet de Lemos, 1999. Tradução de: The changing context of information: an introductory analysis.

MILANESI, Luís. A casa da invenção. 3. ed. São Caetano do Sul: Atelier Editorial, 1997. 271 p.

MILANESI, Luís. O que é biblioteca. São Paulo: Brasiliense, 1983. 107 p. (Coleção Primeiro Passos, 94).

MIRANDA, Silvânia Vieira. Identificando competências informacionais. Ci. Inf., Brasília, v. 33, n. 2, p. 112-122, mai./ago. 2004.

MORESI, Eduardo Amadeu Dutra. Delineando o valor do sistema de informação de uma organização. Ci. Inf. , Brasília, v. 29, n. 1, p. 14-24, jan./abr. 2000.

OLIVEIRA, Jacqueline Rodrigues de. Sistemas de informação: um breve histórico e sua aplicabilidade em bibliotecas universitárias. 2002. Disponível em:

<http://www.sibi.ufrj.br/snbu/snbu2002/oralpdf/63.a.pdf>. Acesso em: 22. jul. 2005.

OLIVEIRA, Jayr Figueiredo de. Sistemas de informação versus tecnologia de informação: um impasse empresarial. São Paulo: Érica, 2004. 140 p. 
PESTANA, Maria Cláudia; PIRES, Pedra Margarete de Siqueira Guidil; FUNARO, Vânia Martins Bueno de Oliveira et al. Desafios da sociedade do conhecimento e gestão de pessoas em sistemas de informação. Ci. Inf., Brasília, v. 32, n. 2, p. 77-84, mai./ago. 2003.

RAMOS, Anatália Saraiva Martins. Sistemas de informação. Natal: [S.n], 2004.

RAMOS, Magda Camargo Lange. A utopia dos bits: impacto das tecnologias de informação na interação bibliotecário/usuário (de graduação) da biblioteca universitária da Universidade Federal de Santa Catarina. 2003. 176 f. Dissertação (Mestrado em Engenharia de Produção) - Universidade Federal de Santa Catarina, Florianópolis, 2003.

REIS, Margarida Maria de Oliveira; BLATTMANN, Ursula. Gestão de processos em bibliotecas. Revista Digital de Biblioteconomia e Ciência da Informação, Campinas, v. 1, n. 2, p. 1-17, jan./jun. 2004.

REZENDE, Denis Alcides; ABREU, Aline França. Tecnologia da informação aplicada a sistemas de informação empresariais: o papel estratégico da informação e dos sistemas de informação nas empresas. 3. ed. São Paulo: Atlas, 2003. 316 p.

SANTOS, Jair Ferreira dos. O que é pós-moderno. São Paulo: Brasiliense, 2004. 111 p. (Coleção Primeiro Passos, 165).

SANTOS, Newton César. A info-barreira. 2002-2005. Disponível em: <http://www.cidade.usp.br/arquivo/artigos/index1301.php\#rodape>. Acesso em: 15. mai. 2005.

SILVA, Sergio Luis da. Gestão do conhecimento: uma revisão crítica orientada pela abordagem da criação do conhecimento. Ci. Inf., Brasília, v. 33, n. 2, p. 143-141, mai./ago. 2004.

SILVA, Wellington Diolice Felix da. Introdução à gestão da informação. Campinas: Alínea, 2003. 96 p. (Coleção Administração \& Sociedade).

SIMON, Imre. Sociedade da informação: temas e desafios. 2000. Disponível em: <http://www.cidade.usp.br/arquivo/artigos/index0301.php>. Acesso em: 20 jul. 2005.

STAIR, Ralph M; REYNOLDS, George W. Princípios de sistemas de informação: uma abordagem gerencial. 4. ed. Tradução Alexandre Melo de Oliveira. Rio de Janeiro: LTC, 2002. 496 p. Tradução de: Principles of information systems.

STÉBILE, Samuel. Um estudo sobre a desconexão entre usuários e desenvolvedores de sistemas de informação e sua influência na obtenção de informação pelo decisor. 2001. 163 f. Dissertação (Mestrado em Engenharia de Produção) - Universidade de São Paulo, São Paulo, 2001.

STUART GARCEZ, Eliane Maria; RADOS, Gregório j. Varvakis. Biblioteca híbrida: um novo enforque no suporte à educação à distância. Ci. Inf., Brasília, v. 31, n. 2, p. 44-51, mai./ago. 2002.

TAKAHASHI, Tadao (Org.). Sociedade da Informação no Brasil: livro verde. Brasília: Ministério da Ciência e Tecnologia, 2000. 195 p.

VERGUEIRO, Waldomiro. Seleção de materiais de informação: princípios e técnicas. 2. ed. Brasília: Brinquet de Lemos, 1997. 126 p. 
VIDOTTI, Silvana Aparecida Borsetti Gregorio; SANCHES, Silviane Aparecida. Arquitetura da informação de web sites. 2004. Disponível em:

<http://libdigi.unicamp.br/document/?view=8302> . Acesso em: 15. jun. 2005.

\section{Patrícia Maria Silva}

Mestranda do Programa de Pós-Graduação em Ciência da Informação da UFPB;

Especialista em Gestão Estratégica de Sistemas de Informação pela UFRN;

Bibliotecária-chefe do Conselho Regional de Medicina do Estado de Pernambuco.

bibcrmpe@cremepe.org.br

Recebido em: 04/12/2006

Aceito para publicação em: jun. 2007 